\title{
Study on the Anatomy of Young Coffee Plants Coming from Micro-Cuttings and Induced to Sprout
}

\author{
Paula Cristina da Silva Angelo ${ }^{1}$ \\ Embrapa Café/Instituto Agronômico do Paraná (IAPAR). CP 10.030. CEP 86057-97, \\ Londrina-PR., Brazil
}

Key words: Anatomy, Young coffe plants, Micro-cutting, Induced sprout

\begin{abstract}
Micro-cuttings coming from Catucaí coffee plants were established in the greenhouse and treated to sprout by decapitation and application of $600 \mathrm{mg} /$ triiodobenzoic acid. The morphology and the anatomy of treated and control plants were compared. Treated plants produced only orthotropic sprouts, useful for micro-cutting, while control plants produced only plagiotropic sprouts. Direct connections between the orthotropic sprouts and the petiole accessory veins were observed only in treated plants. All together, these results were interpreted as consequences of disturbances in the auxin transport systems, which shape apical dominance and bud dormancy.
\end{abstract}

\section{Introduction}

Most of the Arabica coffee genotypes recommended for cultivation nowadays are highly productive, display adequate plant height and architecture and simultaneously are resistant to one or more diseases. The expression of all these traits in a same plant results from long lasting processes of breeding and selection that can even include interspecific hybridization between plants of different ploidy levels. The efforts made to attain this phenotypic complexity and richness justify investing in vegetative propagation of plants selected from heterozenacy progenies of early breeding cycles. A process for in vitro cloning through somatic embryogenesis has, indeed, been applied to Arabica coffee plants (Rezende et al. 2012).

Nevertheless, the price estimated for in vitro cloned plants ready to sow is still considered high in comparison with the price for plants grown from seeds. For this reason, micro-cutting has been evaluated as a procedure to reduce in vitro propagation costs for selected coffee genotypes (Vos and Snijder 2000, Georget et al. 2017).

*Author for correspondence: < paula.angelo@embrapa.br>

DOI: https://doi.org/10.3329/ptcb.v29i2.44507 
Coffea canephora and C. arabica plants produce orthotropic and plagiotropic branches. The main stems are orthotropic, meaning that they grow vertically, and display continuous axillary bud differentiation on two similar and opposite plagiotropic reproductive branches per node, indeed characterizing monopodial growth with sylleptic (immediate) branching. On their turn, plagiotropic reproductive branches grow with a slanted habit and produce inflorescences and secondary order plagiotropic branches (de Reffye 1981, Moens 1968). It is important to notice that plagiotropic branches will not give rise to orthotropic ones, with very rare and fortuitous exceptions. Consequently, plants produced by cuttings taken from plagiotropic branches display unusual architecture.

Moens (1968) described the axillary meristematic cores in the basal nodes of the Arabica coffee main vegetative orthotropic stem as a series of four or five buds organized on each cauline leaf axil. The most medial and/or apical bud in each series - the "head of the series" - gives rise rhythmically, by syllepsis, to the plagiotropic reproductive branches, as described above. The "buds of the series" remain in the leaf axils, and can produce axillary orthotropic vegetative branches of first order (the orthotropic branches of replacement) or, rarely, inflorescences, by prolepsis. Prolepsis means that emergence follows a period of dormancy (Barthelemy and Caraglio 2007).

Previously, present author decapitated and applied successive pulses of triiodobenzoic acid (TIBA), an auxin translocation inhibitor, to acclimatize in vitro cloned Arabica coffee plants, in order to stimulate axillary buds to burst and harvest the axillary orthotropic sprouts, which were used as sources of micro-cuttings for vegetative propagation (Angelo et al. 2018a,b).

The aim of this study was to analyze, at the tissue level, the effects of the treatment applied to induce young Arabica coffee plants from micro-cuttings to sprout while compared to micro-cuttings growing untreated. Through the analysis of the morphology and the anatomy it was possible to demonstrate that micro-cuttings maintained the ordinary young coffee plant structure and also to estimate their capacity to enter additional cycles of sprouting if stimulated.

\section{Materials and Methods}

Plants of Coffea arabica L. cv. Catucaí (567) were cloned in vitro (clone was designated as 3-32 in the laboratory) from leaf explants through somatic embryogenesis (Rezende et al. 2012). Catucaís are highly productive cultivars resistant to the coffee leaf rust caused by Hemileia vastatrix. The treatments applied to produce and establish the micro-cuttings were previously described. Shortly, three months after the transference to the greenhouse, the in vitro cloned plants had resumed growth, and became acclimatized. Acclimatized plants were decapitated and received successive pulses of 2,3,5-triiodobenzoic acid (TIBA) in different concentrations combined or not with benzylaminopurine. These treatments stimulated the sprouting of axillary orthotropic branches, 
which were collected and sectioned in nodal segments to prepare micro-cuttings. Microcuttings established, and succeeded to root and resume growth 90 days after planting (Angelo et al. $2018 \mathrm{a}, \mathrm{b}$ ).

Six month-old established micro-cuttings were transferred from 50-cell plastic trays to conic tubes with capacity to $300 \mathrm{ml}$. A week later, two groups of 40 plants were organized. Plants in the first group (treated plants) were decapitated and sprayed with $600 \mathrm{mg} / \mathrm{TIBA}$ in $1: 1$ ethanol : water. Plants in the second group (control plants) were sprayed with 1 : 1 ethanol : water. Two months after this first pulse of sprouting stimulation, plants in the first group were decapitated and treated with $600 \mathrm{mg} / \mathrm{TIBA}$ a second time. Three months after the second pulse of sprouting stimulation, all the plants were collected, fixed in ethanol $70 \%$ and maintained in the refrigerator for further examination under the microscope. The ethanol solution was replaced by FAA (formaldehyde : acetic acid : ethanol $70 \% 1: 1: 18$ ) when necessary to harden the material. Stainless steel razor blades were used for hand made slices, which were stained in $0.1 \%$ basic fucsin in $50 \%$ ethanol, mounted on glass slides and sealed with acrylate. Glass slides were examined in the same or the next day under a light microscope.

\section{Results and Discussion}

The disturbance in auxin production and translocation caused by decapitation and application of TIBA to the young coffee plants can be inferred by the differences observed in the internodes length of treated and control plants. Control plants grew with internodes 1.5 - 2.0-folds longer than the treated ones (Fig. 1a,b,c).

Control plants produced only plagiotropic sprouts, on distal nodes, starting by the time of the development of the 6th to the 8th node on the main orthotropic stem (Fig. 1a). These data are in accord with Arcila-Pulgarin et al. (2002), who reported that the plagiotropic branches are produced only when coffee plants, or cuttings, display six or more nodes on the orthotropic main stem. Accordingly, Moens (1968) stated that the first pair of plagiotropic branches was produced when $C$. arabica plants germinated from seeds present 8 to 11 nodes, or even later depending on the variety. Differently, treated plants did not launch plagiotropic sprouts, but all of them produced at least one, and rarely two or more, orthotropic sprouts at each one of the leaf axils on the main stem (Fig. $1 b, c)$.

Nodes morphology on treated and control plants was quite different (Figs 2a-a, 3a). On treated plants a characteristic and exclusive thickening, resembling a cork (Moens 1968), which detached very easily from more internal tissues was observed (Fig. 2a-a" and $\left.2 c^{\prime}\right)$. From these nodes, the orthotropic axillary sprouts emerged, a few transverse planes above the leaf petiole, genuinely on the leaf axil (Figs 2a-a", f). Rarely, and mostly from distal nodes, more than one orthotropic sprout or differentiating bud were observed in a same leaf axil (Fig. 2c,d). More often, one orthotropic sprout was observed just above (Fig. 2b-b") or side by side to additional buds being formed (Fig. 2b-b',c") and/or going on differentiation (2c') in the same leaf axil. 


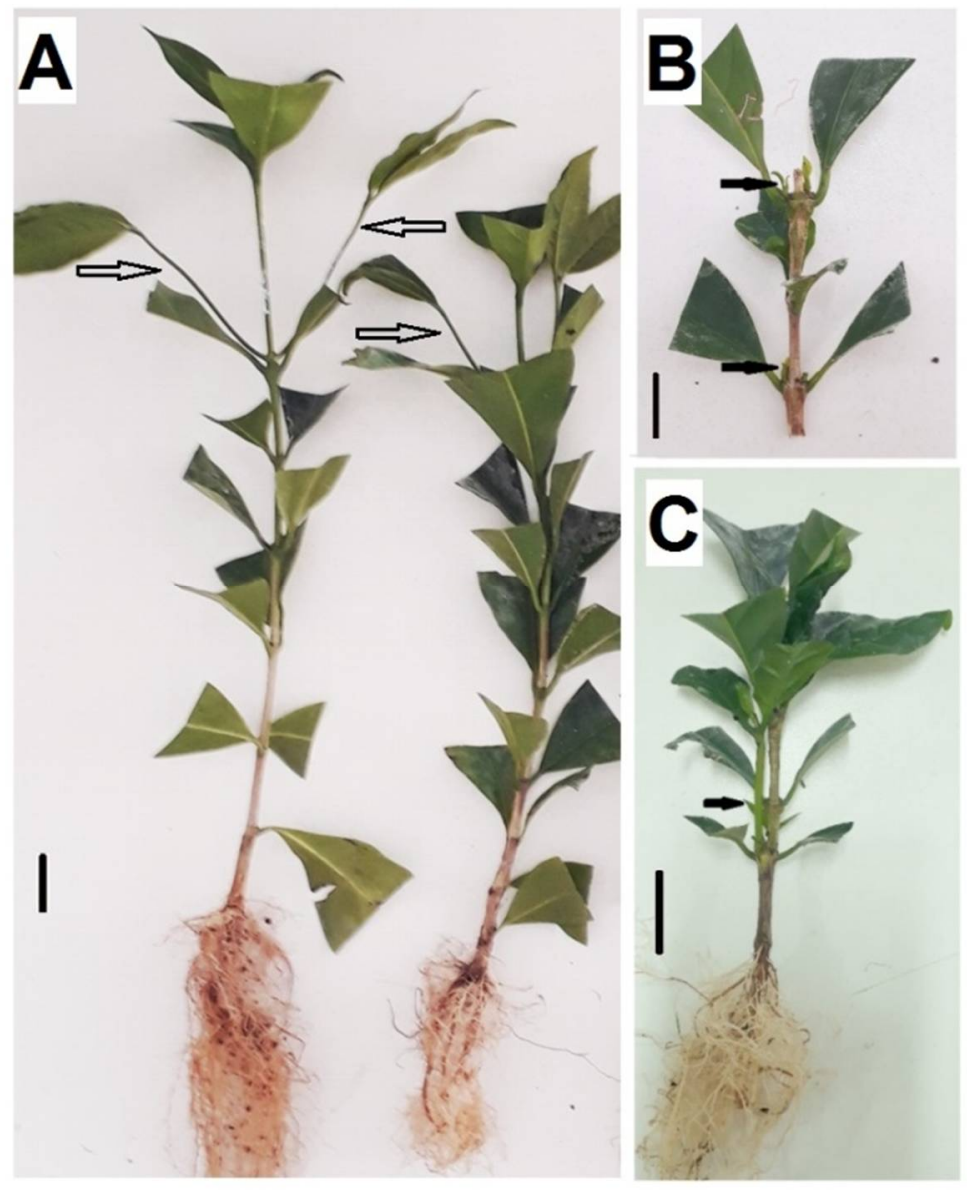

Fig. 1. Overview of coffee plants grown from micro-cuttings non-subjected (A - control plants) and subjected (B and C - treated plants) to decapitation and triiodobenzoic acid application, in order to induce axillary buds outgrow. Empty arrows: plagiotropic sprouts. Solid arrows: orthotropic sprouts. Bars $=1 \mathrm{~cm}$.

By their turn, on the apical nodes of control plants, plagiotropic sprouts emerged from the main orthotropic stem 2 - $3 \mathrm{~mm}$ above the leaf axil, from the "head of the series" (Fig. 2), and grew in angles broader than $45^{\circ} \mathrm{C}$ in relation to the main orthotropic stem (Figs 1a and 3a) contrasting with the axillary orthotropic sprouts that emerged vertically in very acute angles in paralel to the main stem on treated plants (Figs 1b,c and 2a). Buds were not observed around the point of emergence of plagiotropic sprouts on control plants (Fig. 3b-b'). In these control plants, "a conic meristematic region with a series of buds on variate stages of development"- the "buds of the series" (Moens 1968) - and a meristematic core (Fig. 3c-c') were observed $2-3 \mathrm{~mm}$ below the plagiotropic sprout emergence point. 


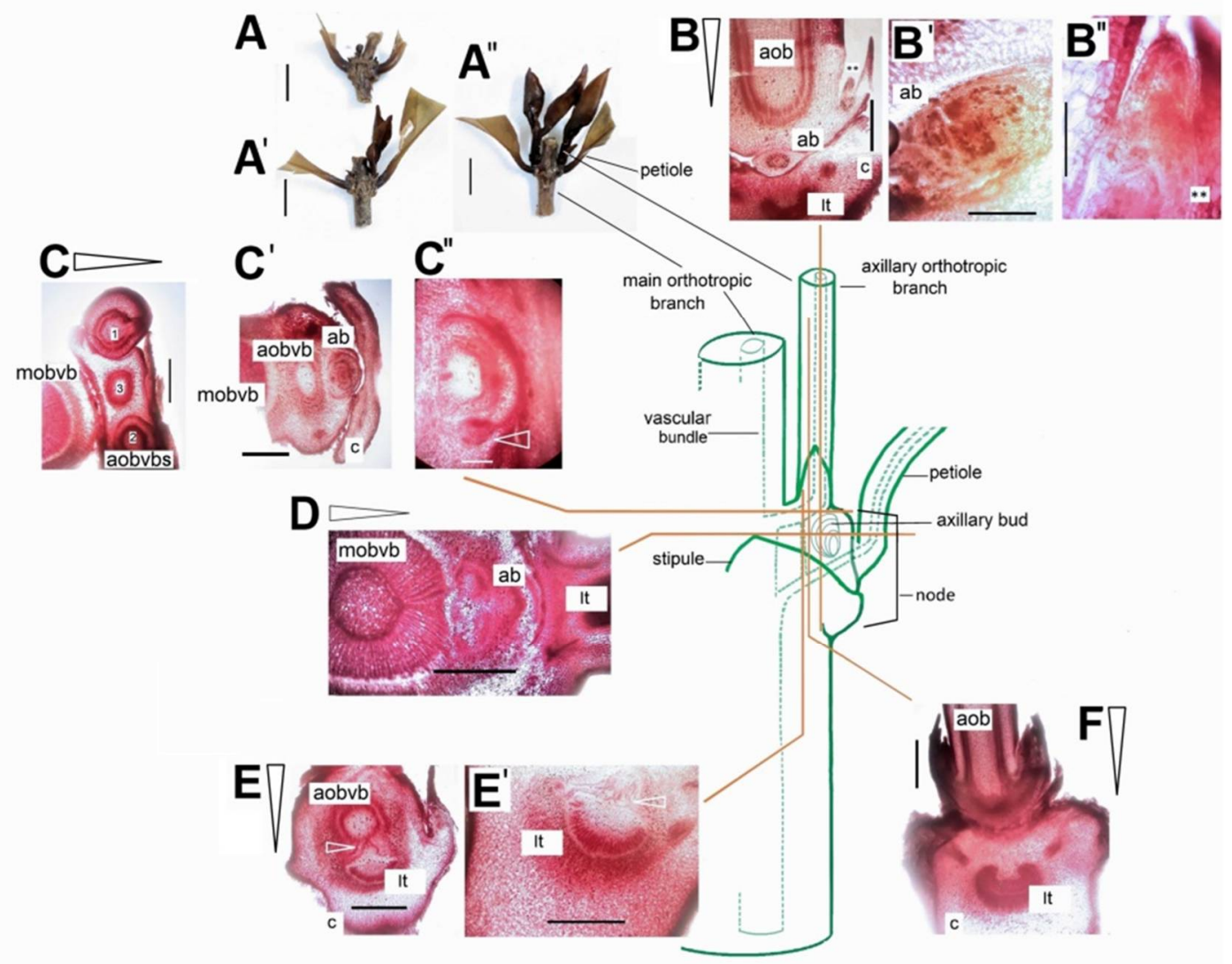

Fig. 2. Stem anatomy of Arabica coffee plants grown from micro-cuttings and subjected to decapitation and application of triiodobenzoic acid solution in order to induce axillary sprouts to burst. The cartoon in the center is an approximate reconstitution of the structures examined. Orange lines and arrow heads next to the images indicate the position and orientation of the sections. Where there are more than an image indexed by the same letter, the sectioning plane is the same in different samples. A-A" - biological sample dissected. A - apical node, $\mathbf{A}^{\prime}$ - intermediate node and $\mathbf{A}^{\prime \prime}$ - basal node. B-B" - longitudinal section of an orthotropic sprout displaying a leaf primordia $\left(\mathbf{B}^{\prime * *}\right)$ which developed above an axillary bud ongoing differentiation $\left(\mathbf{B}^{\prime}\right)$. Bars are $1 \mathrm{~mm}$ for $\mathbf{B}, 250 \mu \mathrm{m}$ for $\mathbf{B}^{\prime}$ and $\mathbf{B}^{\prime \prime}$. $\mathbf{C}$ - transverse sections of nodes, displaying two differentiated axillary orthotropic branches (C) or one axillary branch and one axillary bud already differentiating $\left(\mathbf{C}^{\prime}\right)$ in addition to an undifferentiated dormant tiny axillary bud in the same node (arrow head in $\mathbf{C}^{\prime \prime}$ ). Bars are $1 \mathrm{~mm}$ for $\mathbf{C}$ and $\mathbf{C}^{\prime}$ and $500 \mu \mathrm{m}$ for $\mathbf{C}^{\prime \prime}$. $\mathbf{D}$ - transverse section of a node displaying the traces of the vascular bundles from two axillary orthotropic branches and one axillary bud (right) in differentiation between the main orthotropic branch and the leaf petiole. Bar is $500 \mu \mathrm{m}$. E - longitudinal section of the node to show the vascular connections between a petiole lateral vein and the emerging orthotropic branch. Axillary buds were found in closer vicinity to the leaf petiole, and hit by more tangential/ateral sections, as those depicted in B. White empty arrow heads point to vascular cell strands, which were observed only in treated plants. Bars $=1 \mathrm{~mm}$. F - longitudinal section through an axillary orthotropic branch and the node below, to observe the main petiole vascular bundle (leaf trace) and the two lateral petiole accessory veins above the leaf trace. $\mathrm{Bar}=1 \mathrm{~mm}$. $\mathbf{a b}=$ Axillary bud, $\mathbf{a o b}=$ Axillary orthotropic branch, aobvbs $=$ Axillary orthotropic branch vascular bundles, $\mathbf{c}=$ Cork, $\mathbf{l f}=$ Leaf trace, mobvb $=$ Main orthotropic branch vascular bundle. 


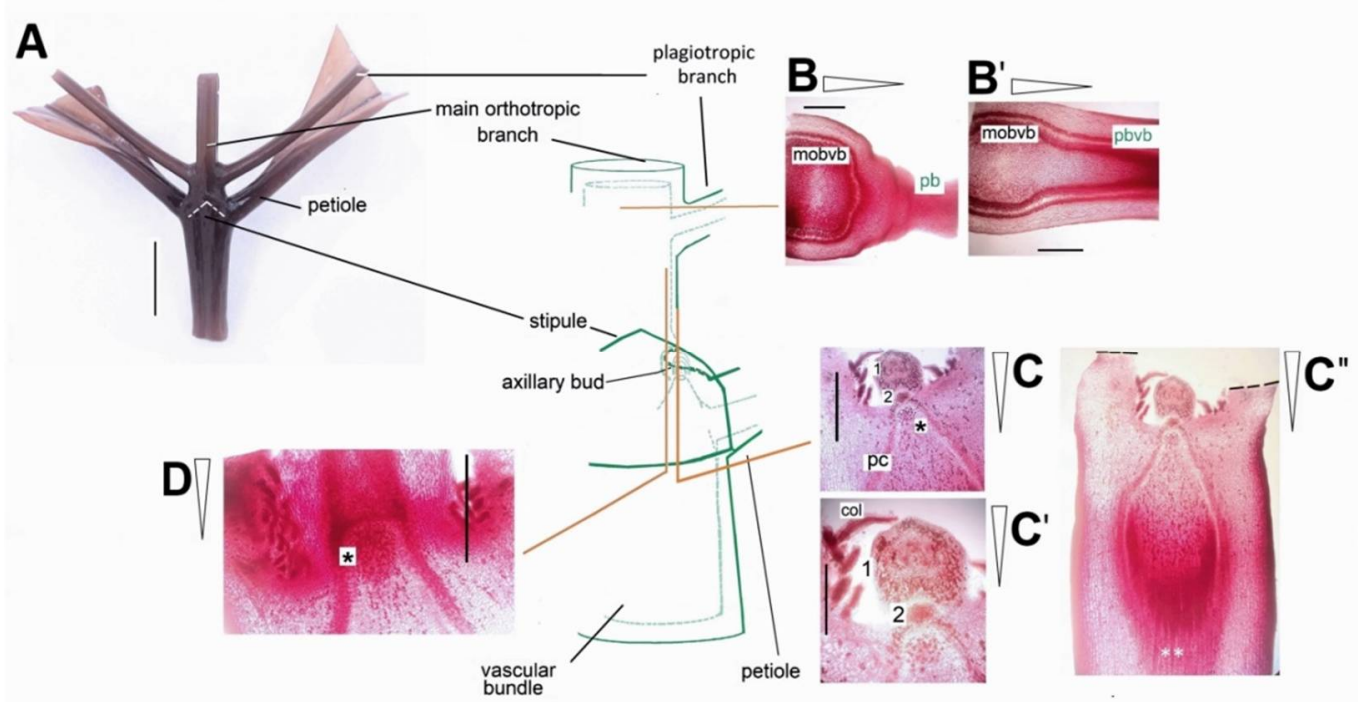

Fig. 3. Stem anatomy of Arabica coffee plants coming from micro-cuttings which were not subjected to sprouting induction treatments (control plants). The cartoon in the center is an approximate reconstitution of the structures examined. Orange lines and arrow heads next to the images indicate the position and orientation of the sections. Where there are more than an image indexed by the same letter, the sectioning plane is the same in different samples. A - biological sample dissected. The stipule was highlighted by white dashes. Bar $=1 \mathrm{~cm}$. B-B" - transverse sections through the insertion of the plagiotropic branch in the main orthotropic stem. Bars $=1 \mathrm{~mm}$. C-C" - axillary buds ongoing differentiation. The uppermost (1) is the first "bud of the series". The next in the series (2) has already developed the procambial strands and there is, apparently, a remnant meristematic core below all of them (asterisk). White asterisks in C" are vascular cell strands from the main stem, which run in a different longitudinal plane than the leaf bundle. Black dashes in C" indicate the point of section rupture where tissue strips trasversing the node from above and below at the laterals of the bud "niche" became too thin to be mounted on the slide. Only the structures in the internode below the buds are depicted. $\mathbf{D}$ - vascular bundles of the main stem running continuously from above and below the bud "niche" a few longitudinal planes ahead the bud "niche", to show that important vascular connections to the accessory petiole veins were not present in control plants. The * indicates the position of a meristematic core. $\mathbf{C o l}=$ Colleters, which produce the protective resinous exudation that cover coffee buds of all types (Mayer et al. 2013), cover the internal surface of the bud "niche". mobvb = Main orthotropic branch vascular bundle; $\mathbf{p b}=$ Plagiotropic branch; $\mathbf{p b v b}=$ Plagiotropic branch vascular bundle; $\mathbf{p c}=$ Procambium. Bars in B-B' $=1 \mathrm{~mm} ; C=1 \mathrm{~mm} ; \mathrm{C}^{\prime}=500 \mu \mathrm{m} ; \mathrm{D}=1 \mathrm{~mm}$.

The less developed buds were observed more often below and a few occasions lateraled in relation to the orthotropic sprouts emerging from the same leaf axil (Figs 2c'$c^{\prime \prime)}$, and this partially agrees to the observations by Moens (1968). This author reported that "until the 8th node" the "buds in the series" would remain undifferentiated. Instead, the "heads of a series" would be "displaced by the natural stem elongation process to occupy a position above the leaf axil" where it is committed to the development of plagiotropic branches.

The formation of axillary meristems is currently based on the theory of the "detached meristem". According to this theory, axillary meristems are produced by a few cells of 
the apical meristem, early designated for the function, which detach from the main meristem core (mother cells group), take place in the boundaries or peripheral zone, and became associated to the leaf axils as soon as the profills start differentiation (Evert 2006, Wang and Jiao 2017). Therefore, the results presented here under the light of the currently accepted theory make it more plausible to consider that in coffee the process of elongation of the main stem is simultaneous to the detachment of axillary meristem founders to occupy the peripheral zone, where some of them constitute the "head of the series", which promptly differentiates in plagiotropic branches, by syllepsis, while some others remain undifferentiated, eventually producing "buds of the series". The "buds of the series" would enter dormancy, under dominance of the sylleptic plagiotropic sprout in the same axil. The emergence of branches can contribute to inhibit the outgrowth of axillary buds on the same node (Prusinkiewicz et al. 2009). And so, on treated plants orthotropic sprouts exert dominance over the buds sharing the same leaf axil. That dominance, however, would present short periods of relief, sufficient to allow buds multiplication but not to allow continuous bud differentiation.

Treated and control young coffee plants coming from micro-cuttings belonged to the same clone, sharing the same genotype and age. And so, why treated plants produced only orthotropic sprouts and control plants produced only plagiotropic sprouts by the activation of similar meristematic cores present on similar young orthotropic main stems?

The molecular basis for the branching process has been recently reviewed (Barbier et al. 2019). A recent model considers that transportation of auxin between source (the plant apex) and sink (the intermediary and basal phytomers in the main stem) occurs through the polar auxin transport system (PATS), a high conductance high polar (basipetal) system, produced through the stable polarization of the auxin efflux carrier PIN1 at the basis of the cells in the xylem associated parenchima and in the cambium. In addition to PATS, the CAT (connective auxin transport) system is produced through the expression of PIN3, PIN4 and PIN7 genes in plant tissues not so closely associated to the vascular bundles, and promote non polar - low conductance transport of auxin molecules from the cell cytoplasm to the apoplast, allowing lateral communication at the local level, granting that auxin can move surrounding stem tissues. PATS and CAT establishment occur in association and concomitantly with the vascularization of new formed organs and meristems, and the genes coding for PIN efflux carriers are all responsive to auxin (Bennett et al. 2016). Auxin, nevertheless, stays out of the buds. Despite it does not enter the buds, a high concentration of auxin in the main vascular stream would interrupt its efflux from the buds, indirectly inhibiting or at least reducing bud outgrowth. In addition, auxin derived from the plant apex also inhibits the expression of cytokinin synthesis genes in the stem (Tanaka et al. 2006, Barbier et al. 2019). Cytokinin is supposed to travel through the main stream and enter the buds to stimulate outgrowth, when auxin is depleted at or below the node that is going to be activated (Müller and Leyser 2011). 
Indeed, it is hypothesized that, for the six months old treated coffee plants coming from micro-cuttings, decapitation provoked a huge reduction of the auxin contents in the main stem, which was composed by four to five phytomers only. This depletion caused the efflux of auxin from the axillary buds through the PATS and the CAT. The decrease in auxin contributed to increase the synthesis of cytokinins in the stem. Tanaka et al. (2006), working with pea plants, proposed that auxin in the stem represses adenosinephosphate-isopentenyl transferase (IPT) genes, which are essential for cytokinin biosynthesis. TIBA, while inhibiting auxin transport along the stem, can enhance IPT expression and function as an aid for decapitation. Nevertheless, ten hours after decapitation, auxin (indol-3-acetic acid) produced de novo in a new formed plant apex, which formerly had been a sub-apical dormant bud, was found in pea stems, increasing auxin concentration and leading to a decrease in IPT expression.

Therefore, going back to previous hypothesis, when the transient effect of TIBA ceased, the influence of a newly organized plant apex added to the influence of emerging orthotropic sprouts in subapical leaf nodes, both auxin sources, simultaneously induced the decrease in the rate [cytokinins/auxins] inside axillary buds below them favoring paradormancy and interrupting bud burst.

To bring the delay in the emergence of branches at all in control plants until they had produced six or so nodes and the absence of plagiotropic branches on the Arabica coffee treated plants in alignment to the same hypothesis, it is considered that plagiotropics emergence depends on a slighter decrease in the auxin content. This exigency could be fulfilled by proper polarization of the PATS and/or by the introduction of some distance between apex and roots, where there is an opposite auxin gradient (Evert 2006), to allow intermediate phytomers unload, and auxin to be exported from the upper phytomers to the unloaded intermediate ones. Local efflux of auxin through the CAT would be essential as well.

Concerning anatomical differences in the vascular bundles, in treated coffee plants delicate cell strands were observed to promote the direct connection between differentiated axillary orthotropic sprouts and the lateral accessory petiole vein below (Figs 2e-e', white arrow head). Differently, in control plants, direct connection between the lateral accessory petiole veins and the procambium or the axillary bud were not observed (Fig. 3c-c"', d). Similar modifications in the vascular bundles were described for the Arabidopsis max4 mutants. These mutants over-express auxin efflux carriers, specially PIN1, and display intensive transport of auxin through the PATS, loosening the capacity to maintain bud dormancy under the control of the shoot apex. In addition, in max4 mutants at least one of the lateral petiole veins connects to the axillary branches more frequently than it does in wild type plants. In wild type Arabidopsis plants both the lateral petiole veins fuse to the main petiole bundle to join the leaf trace in very high frequencies (Bennett et al. 2006, Ongaro et al. 2008). Indeed, on the treated coffee plants, the intense disturbance of the auxin polar transport inflicted by intermittent decapitation and application of TIBA produced effects similar to those caused by the PIN1 auxin efflux 
carrier over-expression in max4 mutants, creating the conditions for the outgrowth of axillary orthotropic branches and for the multiplication of buds placed in all the main stem nodes. The connection of orthotropic axillary sprouts to the petiole and to the main stem stream reinforced their dominance over the buds in the same leaf axil. These buds would relay on the CAT system to transport auxin out and on cell-cell transportation for other solutes necessary to maintain cellular activity.

The importance of the PIN3, PIN4 and PIN7, which compose the CAT, for the production of branches growing in obtuse angles, as the orthotropics, was reported by Bennett et al. (2016): branches produced by pin3, pin4, pin7 Arabidopsis mutants emerge from main stems in broader angles than branches emerging from wild type plants. Considering that TIBA affected mainly the PATS, an increase in the CAT activity could explain why the sprouts observed on treated plants were all orthotropics.

Decapitation and application of sprouting induction pulses five months apart of each other in the previous works (Angelo et al. 2018a, b) induced the first orthotropic sprouts to emerge from the upper remnant node. Differently, decapitation and application of two pulses of TIBA in two months as discussed here more frequently induced the emergence of the first axillary orthotropic branches following the second pulse to occur on the basal nodes (Fig. 1c). This could be imputed to the existence of activated buds on those older phytomers, which should be relieved from dominance at first and subsequently induced to differentiate and elongate, while more apical buds could be already under the dominance of a lower number of auxin sources, despite relatively young and less prepared to emerge.

Six month-old coffee plants from micro-cuttings demonstrated to have ordinary anatomy and organization of meristems. And based on the frequency of dormant buds in the cauline leaf axils of treated plants, additional cycles of sprouting induction would succeed, contributing well to reduce the costs for in vitro cloning.

\section{Acknowledgments}

The authoress is thankful to FAPEMIG (APQ-00149/15) and Fundação Procafé/Embrapa Coffee (SEG 03.17.00.018.00.00) for the financial support, and to Drs. Miguel Pedro Guerra and Paulo Cesar P. Fermino Jr., from the University of Santa Catarina (UFSC, Brazil), for the encouragement for the submission of the manuscript.

\section{References}

Angelo PCS, Baldim DS, Neves PFC, Lacerda JR, Silva, JMD, Couto IE, Bueno IF, Carvalho CHS, Borato PB and Paiva ACRS (2018a) Use of TIBA and BAP on Coffea arabica clones to induce sprouting for micro-cutting. Acta Hortic. 1224: 67-72.

Angelo PCS, Bueno IF, Reis AM, Bartelega L, Carvalho CHS, Paiva ACRS and Matiello JB (2018b) Sprouting induction for micro-cutting on in vitro cloned Arabica coffee plants. Coffee Science 13: 489-497. 
Arcila-Pulgarín J, Buhr L, Bleiholder H, Hack H, Meier U and Wicke H (2002) Application of the extended BBCH scale for the description of the growth stages of coffee (Coffea spp.). Annual Applied Biology 141: 19-27.

Barbier FF, Dun EA, Kerr SC, Chabikwa TG and Beferidge CA (2019) An update on the signals controlling shoot branching. Trends Plant Sci. 24: 220-236.

Barthelemy D and Caraglio Y (2007) Plant architecture: a dynamic, multilevel and comprehensive approach to plant form, structure and ontogeny. Ann. Bot. 99: 375-407.

Bennett T, Sieberer T, Willett B, Brooker J, Luschnig C and Leyser O (2006) The Arabidopsis MAX pathway controls shoot branching by regulation of auxin transport. Curr. Biol. 16: 553-563.

Bennett T, Hines G, van Rongen M, Waldie T, Sawchuk MG, Scarpella E, Ljung K and Leyser O (2016) Connective auxin transport in the shoot facilitates communication between shoot apices. PLos -Biol. 14: e1002446.

de Reffye P (1981) Modèle mathématique aléatoire et simulation de la croissance et de l'architecture du caféier Robusta. I. Etude du fonctionnement des méristèmes et de la croissance des axes végétatifs. Café, Cacao, Thé 25: 83-104.

Evert RF (2006) Esau's Plant Anatomy. $3^{\text {rd }}$ Edition. Wiley. 2006. pp. 103-165.

Georget F, Courtel P, Garcia EM, Hidalgo M, Alpizar E, Breitler J-C, Bertrand B and Etienne H (2017) Somatic embryogenesis-derived coffee plantlets can be efficiently propagated by horticultural rooted mini-cuttings: a boost for somatic embryogenesis. Scientia Horticulturae 216: 177-185.

Mayer J, Carmello-Guerreiro SM and Mazzafera P (2013) A functional role for the colleters of coffee flowers. AoB Plants 5: plt 029.

Tanaka M, Takei K, Kojima M, Sakakibara H and Mori H (2006) Auxin controls local cytokinin biosynthesis in the nodal stem in apical dominance. The Plant Journal 45: 1028-1036.

Moens P (1968) Investigaciones morfológicas, ecológicas y fisiológicas sobre cafetos. Turrialba 18: 209-233.

Müller D and Leyser O (2011) Auxin, cytokinin and the control of shoot branching. Ann. Bot. 107: 1203-1212.

Ongaro V, Bainbridge K, Williamson L and Leyser O (2008) Interactions between axillarybranches of Arabidopsis. Molecular Plant 1: 388-400.

Prusinkiewicz P, Crawford S, Smith RS, Ljung K, Bennett T, Ongaro V and Leyser O (2009) Control of bud activation by an auxin transport switch. PNAS 106: 17431-17436.

Rezende JCD, Carvalho CHS, Paiva ACRS, Pasqual M and Teixeira JB (2012) Multiplication of embryogenic calli in Coffea arabica L. Acta Scientiarum 34: 93-98.

Vos JE and Snijder B (2000) In vitro rejuvenation techniques for the rapid commercial release of clonal coffee plants. Acta Horticulturae 520: 119-126.

Wang Y and Jiao Y (2018) Axillary meristems initiation - A way to branch out. Curr. Opin. Plant Biol. 41: 61-66. 